Faculdade de Ciências Econômicas UFRGS

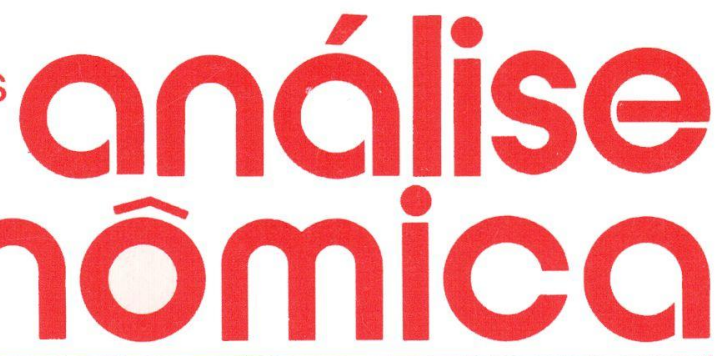

- teoria do balanço de PAGAMENTOS Joáo Luis Tenreiro Barroso

- a IMPORTÂncIa das teorias DE SALÁRIO PARA AS TEORIAS DE INFLAÇÃO Lúcia Maria Góes Moutinho

- os ciclos da economia BRASILEIRA

Vera Beatriz da Silva Oliveira

- SUBSÍDIOS DE PREÇOS AO TRIGO NO BRASIL

Vera Martins da Silva

- A EFICIÊnCIA dA AGRICULtURA GAÚCHA

Juvir Luiz Mattuella

- A economia Regional no BRASIL

Paulo Roberto Haddad

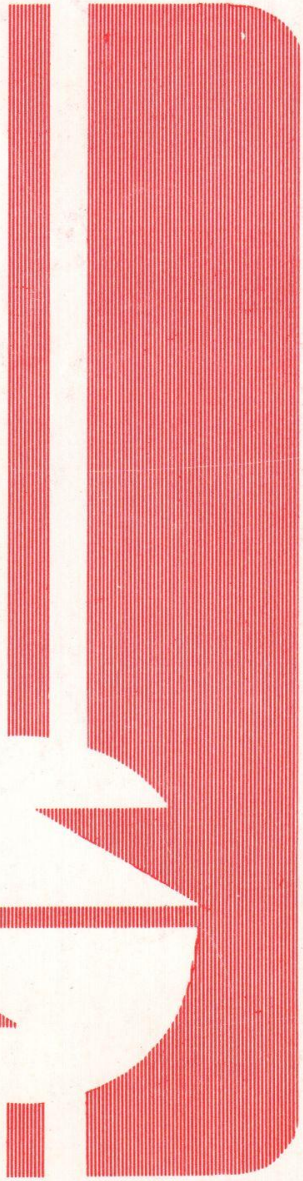


UNIVERSIDADE FEDERAL DO RIO GRANDE DO SUL

Reitor: Prof. Gerhard Jacob

FACULDADE DE CIÊNCIAS ECONÔMICAS

Diretor. Prof. Walter Meucci Nique

CENTRO DE ESTUDOS E PESQUISAS ECONÔMICAS

Diretor: Prof. Reinaldo Ignacio Adams

DEPARTAMENTO DE CIÊNCIAS ECONÔMICAS

Chefe: Profa Oțtlia Beatriz Kroeff Carrion

CURSO DE PÓS-GRADUAÇĀO EM ECONOMIA

Coordenador: Prof. Roberto Camps Moraes

CURSO DE PÓS-GRADUAÇĀO EM ECONOMIA RURAL

Coordenador: Prof. Aray Miguel Feldens

CONSELHO EDITORIAL:

Achyles Barcelos da Costa, Aray Miguel Feldens, Atos Freitas Grawunder, Carlos Augusto Crusius, Ernani Hickmann, João Rogério Sanson, Juvir Luiz Mattuella, Maria Imilda da Costa e Silva, Nali de Jesus de Souza, Nuno Renan Lopes de Figueiredo Pinto, Otília Beatriz Kroeff Carrion, Otto Guilherme Konzen, Paulo Alexandre Spohr, Pedro Cezar Dutra Fonseca, Reinaldo Ignacio Adams, Roberto Camps Moraes, Valter José Stülp, Yeda Rorato Crusius, Edgar Augusto Lanzer (UFSC) e Humberto Vendelino Richeter (UnB)

COMISSĀO EDITORIAL: Atos Freitas Grawunder; Pedro Cezar Dutra Fonseca, Reinaldo Ignacio Adams e Roberto Camps Moraes.

EDITOR: Nali de Jesus de Souza

SECRETARIA: Francisco Carlos Becco dos Santos, Maria Ivone de Mello (normalizaçāo), Vanete Ricacheski (revisão de textos), Wagner Nunes e Zélide Bregaida.

FUNDADOR: Prof. Antônio Carlos Rosa

A Revista ANÁLISE ECONÔMICA publica dois números anuais nos meses de março e novembro. O preço da assinatura, para 1990, é de 7,0 BTNs (o número avulso custa 4 BTNs), a ser pago através de cheque nominal em nome da "Faculdade de Ciências Econômicas/ UFRGS". Aceita-se permuta com revistas congêneres. Aceitam-se, também, livros para elaboração de resenhas ou recensōes.

Toda correspondência, material para publicação, assinaturas e permutas devem ser dirigidos ao seguinte destinatário:

PROF. NALI DE JESUS DE SOUZA

Revista Análise Econômica

Av. João Pessoa, 52 - sala 28

90.040 - PORTO ALEGRE (RS) - BRASIL

Telefone: 25-5844 ramal 34 


\title{
OS CICLOS DA ECONOMIA BRASILEIRA NO PÓS-GUERRA
}

\author{
Vera Beatriz da Silva Oliveira *
}

\section{SINOPSE}

Este artigo tem por objetivo a identificação dos ciclos da economia brasileira em suas diversas fases no período 1945/1985, tomando-se por base a análise de indicadores económicos e de aspectos da realidade econômica que possam ter construldo para a ocorrência dos movimentos ciclicos; entendidos estes como desvios de uma tendéncia de crescimento do sistema econômico no longo prazo. Tomou-se como tendência a taxa histórica de crescimento do PIB.

Concluiu-se que, no perlodo analisado, o produto nacional apresentou dois movimentos ascendentes (51/61 e 64/74), ambos seguidos por movimentos descendentes (62/63 e 75/83), caracterizando as flutuações ciclicas. A análise evidenciou a importåncia do Estado, assim como a relação dos ciclos internos com as oscilações conjunturais internacionais, o que demonstra que os ciclos, em uma economia periférica como a brasileira, perdem, em parte, seu caráter endógeno.

\section{INTRODUÇÃO}

No caso do Brasil, no que diz respeito a ciclos, merece particular atenção o período pós-guerra, durante o qual a industrialização brasileira teve seu impulso maior e a economia, como um todo, desenvolveu-se, levando o pals à chamada categoria de economia "em desen-

* Professora da Fundaçăo Educacional Empresarial do Alto Vale do Rio do Peixe (FEMARP), Videira, SC.

ANÁLISE ECONÔMICA

ANO 7 №11

MARÇO/89 p.63-90 
volvimento". O estrangulamento externo decorrente das duas Grandes Guerras exigiu do pals um esforço de industrialização, mas foi o segundo surto substitutivo de importaçōes (aprox. 1947/60) que impulsionou a fabricação de bens de consumo duráveis e de bens de capital, que representam a base do desenvolvimento industrial.'

O perlodo 1945/85, em termos de PIB real, caracteriza-se por apresentar valores continuamente crescentes de produto, indicando evolução da economia brasileira. Todavia, este crescimento nem sempre verificou-se a taxas constantes, e uma simples análise do Gráfico I permite-nos verificar que a evolução do PIB brasileiro fez-se, no período em estudo, a taxas bastante inconstantes, caracterizando oscilações significativas do produto.

Saliente-se, todavia, que apesar destas flutuaçōes, a taxa de crescimento do produto brasileiro permaneceu razoavelmente elevada em todo o periodo, se comparada a taxas agregadas a nivel mundial (Tabela 2).

\section{A EXPANSÃO NO PÓS-GUERRA: $1945 / 1961$}

Especialmente entre 1947 e 1954, o Brasil teve a seu favor um ciclo internacional expansivo, paralelamente a uma situação de abundância de resenas internacionais. Através da utilização das grandes reservas acumuladas durante a Guerra, logo nos primeiros anos, o pals passou a implementar a segunda etapa da industrialização via substituição de importações, durante a qual foram criadas diversas indústrias.

No nosso pals, o perlodo que vai de 1945 até aproximadamente 1962 representa uma fase de expansão', muito embora não tenha havido um crescimento estável do $\mathrm{PIB}, \mathrm{o}$ qual, todavia, apresentou uma taxa média de crescimento da ordem de $6,8 \%$ no período, taxa esta bastante satisfatória se comparada ao desempenho do resto do mundo.

Entre 1945 e 1962, o produto da economia apresenta quedas significativas apenas nos anos de 1953 e 1956. Observa-se que, nestes dois anos, ocorreram frustraçōes da safra agrícola, tendo o produto

1 As fases do ciclo compreendem um movimento ascendente, dividido em recuperaçăo e expansåo, e um movimento descendente, composto por retraçăo e recessắo. 
deste setor caído significativamente. Além disso, os investimentos do Setor Produtivo Estatal ${ }^{2}$ foram fortemente restringidos.

Entre 1945 e 1950, começam a operar os grandes investimentos estatais do período, como a CVRD, a CSN e a Acesita. É, contudo, a partir de 1956 que o Governo investe firmemente no setor de bens de capital.

Entre 1933 e 1955, o processo de industrialização brasileiro foi limitado pela inexistência de bases técnicas e financeiras de acumulação capazes de permitir que se implantasse o núcleo fundamental da indústria de bens de capital, imprescindlvel para que a capacidade produtiva pudesse avançar adiante da demanda. Nestas condiçōes de limitação, o desenvolvimento industrial ficou subordinado à capacidade de importar do pals, de modo que a economia brasileira, como um todo, permaneceu em posição de subordinação ao conjunto da econmia mundial.

Nesta segunda fase do processo de industrialização, são lançadas as bases do setor de bens de capital, muito embora este setor tenha crescido a taxas inferiores às do setor de bens de consumo.

A indústria de transformação como um todo apresenta queda significativa no início da década de 50 , retomando o crescimento a n'veis superiores a $10 \%$ ao ano a partir de 1958. O desempenho da indústria de transformação no perilodo que vai de 1948 a 1962 mostrase, todavia, bastante satisfatório, com algurnas flutuaçōes que não chegam a comprometer fundamentalmente o setor. A indústria como um todo apresenta uma taxa média de crescimento da ordem de $9,5 \%$.

Os fatores condicionantes para o desenvolvimento da indústria foram: a expansão do mercado interno, as políticas protecionistas à indústria nacional e apoio à substituição de importações; os pesados investimentos estatais; a entrada de capitais estrangeiros destinados à produção de bens para o mercado interno; as facilidades credittcias, fiscais, subsídios, etc., concedidos aos investidores privados para aplicação na indústria, assim como o crescimento da oferta agrícola sem a necessidade de grandes investimentos.

Especialmente durante o governo Kubischek (1956/60), a economia brasileira experimentou uma fase de admirável prosperidade, com aumento significativo da taxa de investimentos, tanto do setor público quanto do setor privado.

2 Definiçáo de Cöutinho e Reichstul (1977) para investimentos do Governo no setor de bens de capital. 
Além da indústria automobilłstica, cuja implantação, como era de se esperar, teve caráter tanto prospectivo quanto retrospectivo sobre os investimentos nas áreas afins, foram instaladas a de construção naval, a de material elêtrico pesado e outras de máquinas e equipamentos, ampliando-se, a partir dal, de forma substancial, o setor de bens de capital.

Cabe destacar que boa parte dos investimentos do perfodo, ou foram realizados por empresas multinacionais ou financiados através de banqueiros internacionais. Predominou uma polstica favorável à entrada de capitais estrangeiros, possibilitando investimentos em diversas áreas, como \& o caso da indústria automobillstica. Os investimentos diretos líquidos apresentam, no período 1947/55, uma taxa média de crescimento anual da ordem de $2,25 \%$, taxa esta que passa já a $16,59 \%$ no período 1955/61 (Crusius, 1983), demonstrando, desta forma, o substancial incremento ocorrido na participação estrangeira nos investimentos. Também os empréstimos e financiamentos estrangeiros aumentaram consideravelmente $(12,82 \%$ ao ano, em média).

No final dos anos 50, amplia-se o déficit do balanço de pagamentos. Dadas as dificuldades de financiamento do investimento público e privado, ocorreu a retração do investimento estrangeiro e expandiu-se a divida externa. O Governo precisou valer-se de crescentes déficits fiscais, visando o financiamento do ambicioso Plano de Metas.

Nos anos iniciais de implantaçāo do Programa de Metas, os investimentos foram por demais elevados, o que deve ter provocado a retração dos investimentos privados no final da década de 50, muito embora tenham-se mantido os investimentos do setor público, compensando a queda (Coutinho e Reichstul, 1977).

Os grandes investimentos com elevada relação capital-produto ocorridos neste perfodo, via de regra, adiantaram-se à demanda. No caso da produção de automóveis, por exemplo, tratava-se, na época de implantação, de um tipo de produto inacessivel para a maioria da população. Além disso, grandes projetos apresentam longo período de maturação e são descontínuos no tempo. Cessado os "pacotes" de investimento e os correspondentes efeitos retrospectivos e prospectivos imediatos, se não houver uma demanda a sustentar a produção, a tendência será a estagnação. Por outro lado, não havia, ainda no final do perlodo, um sistema financeiro que sustentasse a intermediação dos investimentos necessários à continuidade do crescimento, e os investimentos demasiados altos do perilodo anterior haviam levado o Estado 
a uma situação de penúria financeira, sem condiçöes de manter o ritmo de investimentos governamentais.

Os desequilíbrios no Balanço de Pagamentos e inflaçäo acelerada ao fim de curtos perlodos de expansão determinam crise interna e são manifestaçōes do esgotamento da fase expansiva, quando agudizam-se os problemas de pagamento da divida externa e externa.

Efetivamente, em fins da década de 50, início da década de 60, passa-se a utilizar maciçamente as reservas disponiveis. Para compensar a saída de capitais, torna-se necessário incrementar as exportaçōes, única fonte de divisas para fazer frente aos pagamentos internacionais. A reforma cambial de 1959 trazia já incentivo às exportaçōes e subsídio seletivo às importaçōes.

O descontrole das polvticas cambial, monetária e fiscal, aliado à perda de competitividade do café no mercado internacional e ao recrudescimento do processo inflacionário, conduz a economia, no início dos anos 60, à estagnação. O nível de preços inicia, a partir do final da década de 50, uma tendência sem precedentes ao crescimento.

\section{A DESACELERAÇÃO: $1962 / 1967$}

A desaceleraçāo do ińlcio da década de 60, acompanhada pelo recrudescimento da inflação, é agravada, em princípios de 1963 , por forte seca que leva o produto da agricultura a niveis muito baixos (crescimento de 1,0\% em 1963 e 1,3\% em 1964).

O esgotamento dos investimentos governamentais acarretou um efeito desacelerador sobre os outros setores da indústria, especialmente sobre o setor de bens de capital e sobre a construção civil. Com exceçāo da classe Extrativa Mineral, todas as demais classes da indústria apresentaram, queda neste periodo.

Cabe destacar que, embora os investimentos estatais tenham revertido, os gastos públicos correntes continuaram aumentando, contribuindo para a agudização do processo inflacionário e, logo, da crise. (Coutinho e Reichstul, 1977).

A aceleração do processo inflacionário (em 1964 a inflação alcança a taxa de $90,5 \%$ ao ano) foi déstruindo a dinamicidade dos processos de financiamento, impedindo o Governo de manter os incentivos anteriormente concedidos sem a utilização de novas fontes de financiamento. 
Nos primeiros anos da década de 60 , agudizando a fase recessiva do ciclo econômico, instalou-se uma crise política, fazendo com que os investidores reavaliassem suas expectativas e terminassem diminuindo os investimentos.

A produçāo, neste período, chegou a crescer menos que a população: em 1963 o PIB per capita apresenta um decréscimo da ordem de $1,2 \%$ em relação a 1962 , e vem a recuperar-se somente a partir de 1967. Somente a partir de 1968 alcançará novamente taxas superiores a $5 \%$ ao ano.

Neste perlodo, foram adotadas pollticas de estabilização que vieram agravar a crise; políticas estas motivadas pelo aumento da inflação, a qual devia-se em parte à própria crise e aos desequilúbrios do setor externo em outra parte.

A partir de 1964, passou-se a considerar a obtenção de altas taxas de crescimento das exportaçōes como uma das metas prioritárias de polfitica econômica. Obteve-se, no perlodo pós-64, um aumento significativo das exportações de manufaturados em relação às de produtos primários devido tanto ao complexo sistema de incentivos criado pelo Governo, quanto à existência de um quadro de comércio internacional favorável.

A conjuntura internacional favorável esgotar-se-ia, porêm, jấ a partir de 1965, quando os Estados Unidos passam a apresentar crescentes déficits comerciais devido aos gastos com a guerra do Vietnam e à emergente concorrência européia e japonesa. Inicia-se um periodo recessivo mundial.

Com as reformas de base instituídas a partir de 1964/65, inclusive com a criação da correção monetária, passa a desenvolver-se o sistema financeiro nacional moderno. Uma vez que as empresas passam a dispor de fontes alternativas e mais promissoras de recursos para seus investimentos, o resultado ébvio é o aumento da produção.

A produção industrial, que havia apresentado uma taxa média anual de crescimento da ordem de 0,2\% em 1963, em 1966 apresenta taxa da ordem de $9,8 \%$ ao ano, decrescendo novamente apenas em 1967, para então recuperar-se fortemente a partir de 1968.

Observa-se, a partir de 1963, queda dos investimentos do setor privado, situação esta agravada a partir de 1964, quando adota-se a política antiinflacionária Campos-Bulhōes. A formação bruta de capital fixo da economia como um todo apresenta-se em queda no período 1962/65. A poĺtica antiinflacionária implementada, por sua vez, passa 
a dar resultados já a partir de 1965, quando a taxa anual passa para $56,8 \%$ e mantếm a tendência de queda nos anos seguintes.

\section{O “MILAGRE ECONÔMICO": 1968/1973}

A partir de 1967, o periodo recessivo da conjuntura internacional cede lugar a uma fase de expansão, iniciando-se no Brasil, paralelamente, um perfodo de crescimento sem precedentes, que ficaria conhecido como o perdodo do "milagre econômico".

Os fatores que permitiram a recuperaçăo a partir de 1967 foram, segundo Tavares e Belluzzo (1982), os seguintes: a reforma fiscal e financeira de 1966, a elevação e a reestruturação das tarifas dos seviços públicos, a negociação externa e o sistema institucional de crédito ao consumidor, estimulando a demanda da indústria automobillstica e de outros bens duráveis. O Sistema Financeiro da Habitação ativou a construção civil residencial; incentivou-se a exportação e a política salarial e de financiamento estimulou a concentração de renda, e conseqüentemente, o consumo da classe média alta.

A partir de 1968, aumentam os investimentos estrangeiros e ampliam-se os créditos internacionais. A entrada maciça de capitais estrangeiros ocorre paralelamente à perda de importância dos acordos bilaterais, ou seja, os negócios passam a ser feitos diretamente com os bancos internacionais, eliminando a negociação direta país/pals. A melhoria relativa das relaçōes de troca entre 1970 e 1973 permitiu a intensificação da contratação de empréstimos externos.

Entre 1966 e 1969, a produção de bens de consumo aumentou mais que a de bens de produção, devido, especialmente, ao mecanismo de Crédito Direto ao Consumidor, atravếs da especialização das financeiras e à utilização da capacidade ociosa existente. De 1971 a 1973, a produção de bens de consumo duráveis apresenta desempenho anual superior a $25 \%$. Verifica-se, neste período, a liderança da indústria manufatureira, especialmente a de bens duráveis e a de capital. Observe-se que a liderança destes setores confirma encontrar-se a economia num processo de expansão. O setor responsável pela produção de bens de capital é o determinante para o crescimento do produto e, nas fases de expansão, os investidores encontram estímulo para aumentar a produção destes bens. No que diz respeito aos bens de consumo duráveis, seu aumento de produção é motivado pelo incre- 
mento dos lucros (uma vez que não houve distribuição de renda) e irá provocar, com sua demanda, incremento na produção de bens de capital.

O setor de bens de capital acelera-se entre 1971 e 1973, caracterizando o auge do ciclo. Em 1972, este setor cresce a uma taxa de $25,7 \%$ e, em 1973 , a $27,7 \%$, taxa superior a todos os demais setores, para então iniciar queda no crescimento. $O$ setor de bens de consumo não-duráveis é o que, efetivamente, começa a sentir os reflexos da desaceleração a partir de 1974 , quando sua taxa de crescimento é de apenas $3,9 \%$, bem menor, portanto, que as taxas de outros setores, especialmente o setor de bens de capital $(22,3 \%)$.

Verifica-se ainda, no período $1967 / 73$, uma abertura estrutural para o exterior, com o crescimento das exportaçōes, motivada pela promoção de minidesvalorizaçōes, e a reinstalação de um abundante fluxo de financiamento externo. Os empréstimos e financiamentos cresceram, neste período, a uma taxa média anual de $42,80 \%$ e os Investimentos diretos líquidos, $52,07 \%$.

Especialmente no período 1968/73, a taxa agregada de inversão da economia sofreu significativa elevação (Tabela 6). O Governo retoma fortemente seus investimentos no final da década de 60, particularmente no setor de produção de bens de capital, levando lentamente a uma reativação dos investimentos do setor privado, os quais adquirem importância apenas a partir de 1970, quando os níveis de capacidade instalada começam a atingir os limites desejados.

A inflação apresenta-se menos variável, tendo inclusive decrescido levemente, com exceção dos anos de 1972, 1973 e 1974, quando houve sensivel aumento, inclusive como indicador do final da etapa de expansão.

Com a criação do mercado de euromoedas após o abandono do lastro-ouro em 1971, rão havia mais segurança quanto aos pagamentos mundiais, isto é, os palses fabricantes de moedas-forte podiam alterar-lhe o valor, transmitindo seus movimentos econômicos internos aos demais palses. Juntando-se a isto, a crise do petróleo, em 1973, veio instalar uma forte crise internacional, que teve como característica principal a coexistência dos fenômenos recessão e inflação.

\section{A CRISE: $1974 / 1983$}

A partir de 1973, apesar do aumento da taxa de investimentos e 
das importações, há uma queda na taxa de crescimento industrial, com conseqüente menor crescimento do PIB.

De meados de 1974 em diante a economia brasileira entra numa fase crftica. O recrudescimento da inflação é acompanhado de um acentuado declínio do ritmo de crescimento da economia. A análise das taxas médias de crescimento de alguns dados macroeconômicos básicos correspondentes ao período 1973/80, tais como PIB, produção industrial, investimentos, preços e comércio externo, evidencia a inflexão ocorrida no ciclo de crescimento. No entanto, a desaceleração, no início do período, esteve longe de configurar uma situação depressiva, uma vez que o PIB cresceu a uma taxa média anual de $7 \%$, que corresponde à tendência histórica do pós-guerra.

Mesmo após o primeiro choque do petróleo em 1973, taxas relativamente elevadas de crescimento para a economia, como um todo, e para a indústria, em particular, continuaram a ser alcançadas até 1981. Isto deveu-se em parte à manutenção do processo de substituição de importações (alcançou-se o objetivo de substituição de importações de produtos intermediários e impulsionou-se a produção de bens de capital), bem como à expansão das exportações industriais e aos elevados investimentos em infra-estrutura.

O agravamento da crise não se deveu apenas ao choque do preço do petróleo, mas também às desproporçōes no crescimento durante o ciclo expansivo e à falta de um controle efetivo das importaçōes no perilodo 1971/72.

Esta desaceleração do crescimento industrial decorreu fundamentalmente dos problemas gerados em relação à demanda de bens de consumo não-duráveis e duráveis, decorrentes da contenção dos salários e da aceleração da taxa de inflação.

Os efeitos acelerados da fase do auge do ciclo expansivo, combinados com os objetivos do II PND, impulsionaram fortemente os investimentos no setor de bens de produção, impedindo a ocorrência de uma crise de grandes proporções. Fica, então, evidente a importância dos investimentos públicos. Mas o investimento público, graças à descontinuidade e porte de seus projetos, não consegue sustentar por muito tempo as taxas de investimento e produção, principalmente quando recrudescem os problemas de Balanço de Pagamentos e endividamento externo.

O financiamento do investimento no setor de bens de capital e insumos básicos, preconizado no II PND, fez-se basicamente a partir 
da utilização de recursos externos, dado o enorme volume de recursos que ingressaram na economia. Este financiamento deu origem a um endividamento externo suicida, devido à falta de alternativas internas capazes de sustentar os ambiciosos investimentos.

O esforço da substituição de importaçōes de bens de capital não foi acompanhado por um esforço correspondente em relação ao petróleo, levando a um acúmulo da dívida externa e a um adiamento dos problemas para o futuro. Além disso, no início do período os juros internacionais ainda não haviam se elevado como a inflação mundial, levando à maciça entrada de capitais "baratos".

A agricultura, por sua vez, cresceu com flutuações devidas a aspectos climáticos, mas o atraso para o mercado interno persistiu também neste perilodo.

Em 1975, evidenciava-se que a polf́tica econômica expansionista, permeada de ambiciosos objetivos, não fazia sentido em meio a uma evidente recessão mundial. No início de 1976, o Governo passa a admtir que algumas metas do II PND não poderiam ser cumpridas, desativando parcialmente o plano. Mas, ainda nesta época, o setor privado continua investindo e o setor público encaminhando grandes projetos. A taxa de investimento global declinou fortemente depois de 74/75 e tanto a relação capital-produto quanto aos prazos de maturação aumentaram.

A taxa de Formação Bruta de Capital Fixo caiu a partir de 1975 com defasagem de um ano em relação à taxa do PIB. Houve uma fase de transição em 1974/75, quando a queda observada foi lenta: $O$ investimento governamental contribuiu para instabilizar e agravar as tendências recessivas, enquanto que os investimentos do setor produtivo estatal exerceram papel antić́clico (Coutinho e Reichstul, 1983).

Em 1975, todos os setores apresentam taxas de crescimento menores e, pela primeira vez, um setor - o setor de bens de consumo duráveis - apresenta taxa real negativa de crescimento.

Após 75, nota-se a adoção de uma política de "stop and go" implementada pelas autoridades econômicas. Alternam-se fases de aceleração e desaceleração, motivadas pela tentativa de ajustar a economia aos problemas conjunturais, que impunham ora mais vagar, na tentativa de reduzir a inflação e minimizar os problemas de Balanço de Pagamentos, ora mais rapidez, na tentativa de retardar a reversão do ciclo.

De 1978 a 1980, mantém-se, para a indiústria, uma taxa de cres- 
cimento em torno de seu padrão histórico, mas manifesta-se a tendência à desaceleraçāo em alguns setores, como bens de consumo nãoduráveis. Os setores que se mantêm crescendo razoavelmente sāo os de bens intermediários e os de bens de consumo duráveis.

A política contencionista, baseada principalmente em juros elevados e aperto creditício, implementada por Simonsen em fins de 1976, logrou levaŕ a economia a um desaquecimento da demanda agregada, partindo do pressuposto de que se tratava de uma inflação de demanda. A contenção do crédito agudiza a aceleração dos preços, urna vez que as empresas vão buscar no mercado financeiro os meios de que necessitam.

O salto inflacionário de $20 \%$ em 1971 para $40 \%$ em 1976 deveuse, em parte, ao recrudescimento da inflaçāo mundial, mas também ao crescimento das taxas de juro depois de 1975, devido à chamada "ciranda financeira". Por outro lado, a insuficiente evolução da disponibilidade de alimentos em relação à população contribuiu significativamente para o agravamento da situação.

No final de 1978, embora ainda apresentando taxa histórica de crescimento do PIB, a economia apresentava uma vulnerabilidade relativamente grande em relação ao setor externo.

Em fins de 1979, instala-se uma política expansionista, mas a inflação continua crescendo a taxas vertiginosas (em 1980 iria atingir a casa dos três dígitos). A política econômica, implementada entre o $2^{\circ}$ semestre de 1979 e o primeiro de 1980, teve como resultado aumento da inflação e perda de reservas, levando à adoção de uma política fortemente ortodoxa no $2^{\circ}$ semestre de 1980 , a qual teria como conseqüência, em 1981, o crescimento negativo do produto e do emprego industrial.

A forte aceleração do preço do petróleo - o segundo choque não somente contribuiu para novo aumento generalizado de preços, como também ocasionou deterioração do Balanço de Pagamentos. A partir de 1979 a restrição externa passou a ser o principal objeto de ajuste econômico.

A relação de trocas, que se mantém crescente de 1974 a 1977, graças à elevação dos preços no mercado internacional de alguns produtos com peso considerável nas exportações, como o café e a soja, cai a partir de então, fruto da recessão que se abateu sobre os palses industrializados; derivada do processo de ajuste destas economias aos dois choques do petróleo, à deterioração dos padrões de comércio in- 
temacional e ao choque das taxas de juro. Fica clara a deterioração dos termos de troca do Brasil com o resto do mundo a partir de 1977 (Gráfico II).

A partir de 1974, os elevados déficits em conta corrente passam a pressionar a dívida externa, levando-a a patamares de tal magnitude que o serviço da dívida (juros mais amortizaçōes) em 1982 representava $96 \%$ das exportações, não obstante as taxas de juro terem declinado a partir de 1982. Neste periodo, houve novo fechamento da economia para o exterior, tendo declinado o coeficiente de importações em relação ao PIB.

O setor externo terminou sendo fator de restriçăo ao crescimento, embora não tenha havido restriçōes sérias às importações até 1980 nem qualquer escassez dramática de divisas. Sem menosprezar os aspectos negativos dos choques externos, deve-se mencionar, todavia, que as políticas monetária, cambial, salarial, de condução da divida externa e de controle da inflação, implementadas em 1979 e 1980, contriburram para o agravamento da crise. Agudizou a crise o péssimo desempenho agrícola de 1979.

Em 1981 e inf́cio de 1982, praticamente todos os grupos de bens, quer por gêneros de bens, quer por categorias de uso, apresentam queda substancial e o desemprego atinge todo o pals. A queda na demanda efetiva ocorrida em 1981 leva a uma desaceleração intensa da atividade industrial, com vista a eliminar estoques acumulados no ano anterior. Assim, criou-se um certo espaço para a reposição desses estoques de forma a aumentar o ritmo da produção industrial, principalmente no setor de bens de consumo. Entretanto, já no último trimestre de 1982, apresentavam-se sinais de nova reversão no ritmo de crescimento da indústria.

O PIB per capita cai a $-5,6 \%$ em 1981: uma taxa negativa sem precedentes.

Dentro do quadro recessivo, que dominou a economia no periodo de 1981/83, destaca-se a queda da participação relativa da formação bruta de capital fixo no PIB (Tabela 6).

Agrava-se, neste inicio dos anos 80 , o problema da dívida externa, pois os credores passam, então, a ditar normas globais de política econômica para todos os endividados; fazendo com que o Governo tome medidas totalmente desvinculadas dos interesses nacionais de crescimento. Em 1982/83, a situação externa fica dramática, levạndo o 
pais a uma forte crise cambial em 1982, que forçou a uma política de ajuste das contas externas com base nos programas clássicos do FMI.

A política de comércio exterior adotada pelo Governo, que consistiu em incentivar exportaçōes e comprimir importaçōes, pode ser comprovada pelo crescimento do coeficiente exportaçőes/PIB que, no perílodo $80 / 83$ passou de $8,8 \%$ a $11,8 \%$, enquanto o das importaçōes caiu de $11 \%$ para $9,3 \%$.

A recessão mundial, aliada ao aumento do protecionismo e à forte valorização cambial do cruzeiro, ocorrida entre janeiro de 1980 e fevereiro de 1983, traria, a partir de 1981, todos os inconvenientes de uma crise cambial. No final de 1982, com o cessar do fluxo voluntário de empréstimos externos, agrava-se, ainda mais, a crise cambial, levando ao péssimo desempenho da economia em 1983.

A completa escassez de divisas levou à implementação de um programa de estabilização econômica. Por outro lado, a tentativa de controle da demanda agregada, sem adequadas medidas complementares no lado da oferta e sobre os mecanismos de indexação, jogam o pals num processo de estagflação.

Apesar da adoção de três polf́ticas salariais diferentes apenas no decorrer de 1983, insentifica-se a inflação e, com ela, a queda do salário real e o desemprego. Neste ano, praticamente todos os setores da economia apresentam taxas negativas de crescimento, tendo ocorrido ainda choques negativos de oferta representados pelas perdas na safra de grāos.

O ano não foi favorável economicamente para o país, quer no âmbito do setor interno, quer no âmbito das contas externas, culminando com a suspensão parcial do pagamento das amortizaçōes da dívida externa vencidas ao longo do período.

\section{RECUPERAÇÃO? 1984/85}

Em 1984, a economia volta a apresentar um crescimento da ordem de 5,7\% em termus reais do PIB. Em termos per capita, 0 índice do produto real acusa uma variação anual positiva de cerca de $3 \%$.

Já no inlcio deste ano, a conjuntura internacional apresentava sinais de recuperação com conseqüente aumento da demanda externa, especialmente devido ao crescimento da economia americana $(8,5 \%$ em 1984). 
Devido á redução do preço do petróleo, à ampliação da produção interna e à implementação dos programas energéticos alternativos, houve redução dos dispêndios com importações e recuperaram-se as exportaçőes de manufaturados.

Apesar do excelente desempenho das contas externas (saldo de US $\$ 700$ milhões após dois anos de pesados deficits), o serviço da divida externa continoū a representar um peso excessivamente alto sobre o setor produtivo interno.

1984 foi um ano de transição política e econômica, durante o qual houve recuperação da produção, com conseqüente reativação do emprego e dos salários, além de uma sensivel elevação da produtividade do salário. A tendência inflacionária diminui o caráter ascendente, passando a inflação a ter um caráter predominantemente inercial, em virtude do processo de indexação plena da economia.

Estimulado pela forte pressão da demanda externa e pela evolução passiva da política de crédito, o setor industrial recuperou-se, apresentando crescimento de 7,0\% em relação a 1983 (Tabela 3). O setor de bens de capital lidera a recuperação, com um crescimento da ordem de $14 \%$.

o conjunto de estratégias utilizadas ao longo de 1985 permitiu uma elevada taxa de crescimento do PIB, $8,2 \%$, superávit considerável na Balança Comercial, US $\$ 12.405$ imilhōes, e ampliação no nivel de emprego, além de um crescimento equilibrado envolvendo praticamente todos os setores. Estas estratégias, contudo, levariam, no final do período, ao recrudescimento do processo inflacionário (taxa anual de 225,5\%).

Em 1985, três fatores podem explicar a alta taxa de crescimento do PIB: as freqüentes e significativas reposiçōes salariais nos setores púbico e privado, devidas à ativação das reivindicaçōes sindicais; o caráter expansionista das pölíticas monetária e fiscal, com taxas de aumento dos agregados monetários (M1) próximas aos $300 \%$ ao ano (portanto, acima da inflação); bem como o comportamento favorável dos preços das matérias-primas importadas, especialmente o petróleo, durante a maior parte do ano. A política salarial expansionista e a elevada liquidez finanœeira levaram a uma expansão substancial do consumo.

Enquanto, em 1984, o crescimento industrial havia se concentrado nas exportaçōes, em 1985, é estimulado pelo mercado interno. A agricultura, por sua vez, apresenta uma taxa de crescimento da ordem de $8,8 \%$. 
Muito embora o desempenho da economia em 1985 possa ser considerado satisfatório, não se pode deixar de considerar o enorme déficit verificado nas contas do setor público, o qual teve como conseqüência, no final do período, aumentos da carga tributária, rigidez das taxas de juro, expansảo monetária e a própria aceleraçãodo processo inflacionário.

\section{CONCLUSÕES}

Considerando-se a taxa média histórica de crescimento no perilodo $1945 / 1985$ da ordem de $6,6 \%$, chega-se à configuração das fases dos ciclos econômicos no Brasil conforme demoristra o Gráfico I.

No período que vai de 1945 a 1961, encontramos certa dificuldade em estabelecer precisamente uma divisão das fases, uma vez que - Produto Nacional apresenta oscilações em torno da média praticamente anuais. A maior parte da literatura consultada classifica este período corno sendo de expansão, quer pelo fato da taxa média de crescimento do perlodo ser bastante significativa $(7,3 \%)$, quer pela especificidade do desenvolvimento alcançado na época, especialmente na década de 50, perilodo de forte industrialização. As constantes oscilações do produto neste perlodo prendem-se, sem dúvida, em grande parte, ao aspecto da participação estatal nos investimentos, promovendo a industrialização por meio de grandes "pacotes" de inversões, bem como à entrada no país de plantas multinacionais específicas, não relacionadas a um plano global de desenvolvimento.

Podemos dividir o periodo em duas fases, sendo que o primeiro de 1945 a 1951, durante o qual o movimento de queda do produto parece indicar uma retração. Após esta fase, todavia, viria a expansão.

O biênio 1962/63 caracteriza um perlodo de recessão, ainda que breve, com taxas de crescimento muito inferiores à média histórica.

A partir de 1964, inicia-se uma fase de recuperação, que iria resultar em expansão, o que se dá por volta de 1967. Esta fase de expansão dura então cerca de 7 anos, atingindo o pico em 1973.

O primeiro choque do petróleo contribui para jogar a economia em um processo de retração econômica que, em 1981, caracterizar-seia como receșsão, alcançando neste e no ano de 1983 taxas negativas de crescimento.

O desempenho no biênio $1984 / 85$ pode caracterizar uma recupe- 
ração, mas dever-se-ia aguardar a observação de dados referentes aos anos subseqüentes para uma inferência mais precisa.

A observação dos dados referentes ao produto nacional e seus diversos componentes e aspectos permite concluir-se, por exemplo, que as categorias bens de capital e consumo duráveis apresentam variaçōes mais significativas, embora todas as categorias, como componentes do PIB, acompanhem suas variaçōes, diferindo apenas em intensidade. Este fato indica a dinamicidade das categorias de bens de capital e consumo duráveis como motores do desenvolvimento. A categoria dos bens de consumo não-duráveis é a que apresenta menor espectro de variação, uma vez que seu desempenho está mais ligado à variável população, bem como que seu crescimento se dá de forma defasada, como decorrência do desempenho dos demais setores e como função da massa de salários e da distribuição de renda.

Os dados de investimentos demonstram a importância destes como elemento de ativação da economia; em vários períodos, nota-se que os incrementos nas inversōes antecedem em um ano os incrementos do PIB. Isto deve-se, em parte, ao período de maturação dos projetos e, por outro lado, ao caráter impulsionador que pacotes de investimentos exercem sobre a economia como um todo.

Ainda no que diz respeito às inversōes, cabe observar que, da análise das mesmas, depreende-se a importância da participação do Estado na economia brasileira. Este aspecto é observado especialmente nos periodos de industrialização. quando o Governo exerceu papel fundamental, quer através da implementaçāo de grandes projetos, quer através da concessão de crédito e facilidades, cumprindo a função de um sistema financeiro ineficiente ou mesmo inexistente.

O Estado, no Brasil, exerceu papel fundamental, especialmente por intermédio de seus planos de desenvolvimento e, na década de 70, através de suas políticas de estabilização. Estas políticas, aliás, podem explicar, em parte, o fato do produto apresentar tantas oscilações no perilodo de retração 75/80.

A obsevação dos preços demonstrou, por outro lado, que esta variável tende a apresentar flutuações inversas às do produto, ou seja, os preços tendem a subir nas fases de recessão. Esta tendência, todavia, é contrariada no perilodo 84/85 quando, em função dos mecanismos de indexação utilizados pelas autoridades monetárias, ocorre exatamente o contrário. Esta questão, todavia, mereceria um estudo à parte.

A análise das relações internacionais e dos indicadores" de co- 
mércio exterior revela outro importante aspecto da economia brasileira: a dependência em relação aos movimentos conjunturais internacionais. Nos periodos iniciais, a dependência baseava-se no incipiente desenvolvimento da indústria brasileira, que necessitava de importaçöes substanciais destinadas a alimentar o processo de industrialização. A necessidade de buscar-se capitais estrangeiros e a ineficiência de sua utilização, na maioria dos casos, geraria um processo de endividamento suicida. Este endividamento acabaria por levar a outro tipo de dependência, desta vez ainda mais profunda em função dos mecanismos de internacionalização, que cada vez mais de desenvolvem.

A relação dos movimentos cíclicos internos corn as oscilaçōes conjunturais internacionais são evidentes, demonstrando que os ciclos em uma economia periférica como a brasileira perdem em parte seu caráter endógeno, ou pelo menos têm a considerar-se mais um fator externo que deverá influenciar em maior ou menor grau os movimentos internos. $\dot{E}$ importante considerar que esta interdependência afeta inclusive a autonomia do governo ern estabelecer eficientemente politicas anticíclicas, possíveis antes do grau de internacionalização da economia brasileira atingir os níveis atuais. 


\section{ANEXOS}

\section{TABELA 1 - PIB DO BRASIL - Nominal, real, taxas de cresci- mento anual}

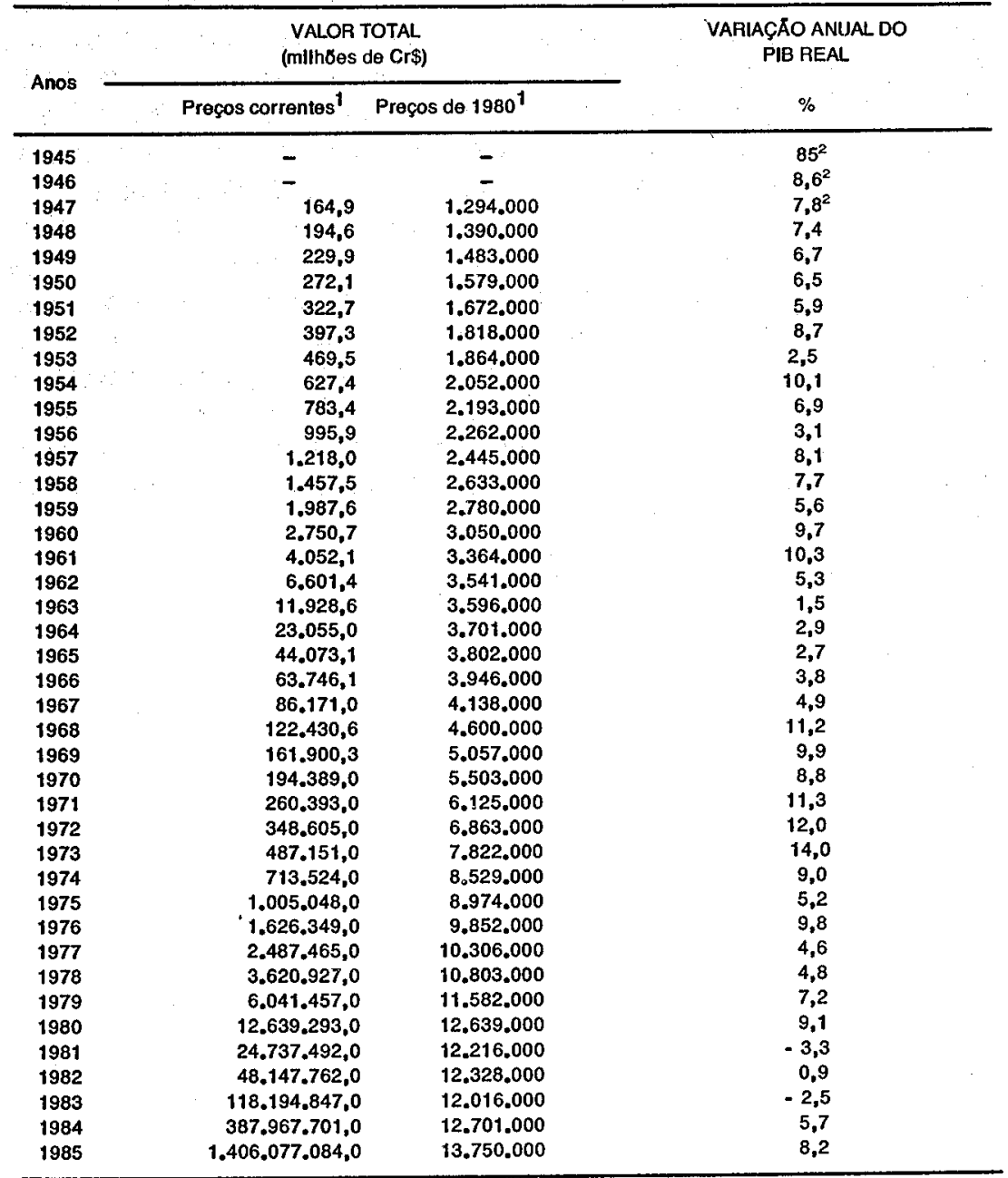

FONTE: Contas Naclonais - Fund. Getúllo Vargas, Rev. Conjuntura Econơmica (1947/64: set. 71; 1965/69: dez. $79 ;$ 1970/85: maio/87)

1 - series equallzadas por relativos.

2 - In: CONTADOR (1977) $1945 / 46$ taxa de crescimento correspondente â mêdia móvel de terceira ordem. 


\section{TABELA 2 - ECONOMIA MUNDIAL - PIB A PREÇOS CONS- TANTES - Variação percentual em relação ao ano anterior}

\begin{tabular}{lccc}
\hline Anos & MUNDO & $\begin{array}{c}\text { PAISES } \\
\text { INDUSTRIALIZADOS }\end{array}$ & $\begin{array}{c}\text { PAISES EM } \\
\text { DESENVOLVIMENTO }\end{array}$ \\
\hline 1955 & - & 6,2 & - \\
1958 & - & 1,3 & - \\
1959 & - & 6,0 & - \\
1960 & 4,4 & 4,4 & 4,3 \\
1961 & 4,3 & 4,2 & 4,7 \\
1962 & 5,2 & 5,4 & 4,3 \\
1963 & 4,7 & 4,5 & 6,0 \\
1964 & 5,9 & 5,8 & 6,0 \\
1965 & 6,0 & 6,1 & 5,5 \\
1966 & 5,5 & 5,5 & 5,1 \\
1967 & 3,7 & 3,6 & 4,3 \\
1968 & 5,4 & 5,3 & 5,9 \\
1969 & 5,3 & 4,9 & 7,6 \\
1970 & 3,2 & 2,7 & 5,9 \\
1971 & 4,0 & 3,5 & 6,0 \\
1972 & 5,3 & 5,2 & 5,7 \\
1973 & 5,6 & 5,5 & 6,4 \\
1974 & 1,4 & 0,2 & 5,8 \\
1975 & 0,4 & $-0,8$ & 4,7 \\
1976 & 5,3 & 5,2 & 5,5 \\
1977 & 4,4 & 3,9 & 6,1 \\
1978 & 4,1 & 4,0 & 4,3 \\
1979 & 3,4 & 3,0 & 4,7 \\
1980 & 1,5 & 0,6 & 4,4 \\
1981 & 1,8 & 1,5 & 2,7 \\
1982 & 0,3 & $-0,2$ & 1,0 \\
1983 & 2,3 & 3,0 & 0,2 \\
1984 & 4,5 & 5,0 & 2,8 \\
1985 & - & 3,0 & - \\
\hline
\end{tabular}

FONTE: FMI - Estadisticas Financieras Internacionales, 1986. 
TABELA 3 - PRODUTO REAL SEGUNDO PRINCIPAIS RAMOS DE ATIVIDADE - 1948/1985 - Taxas de crescimento anual

\begin{tabular}{|c|c|c|c|c|c|}
\hline Anos & & $\begin{array}{c}\text { Setor } \\
\text { Agropecuário }\end{array}$ & $\begin{array}{c}\text { Setor } \\
\text { Industrial }\end{array}$ & Comércio & $\begin{array}{l}\text { Transportes e } \\
\text { Comunicaçס̄es }\end{array}$ \\
\hline 1948 & & 6,9 & 11,3 & 3,2 & 16,6 \\
\hline 1949 & & 4,5 & 10,2 & 6,1 & 8,4 \\
\hline 1950 & & 1,5 & 11,3 & 7,1 & 9,5 \\
\hline 1951 & & 0,7 & 6,4 & 9,7 & 10,8 \\
\hline 1952 & & 9,1 & 5,0 & 3,6 & 7,2 \\
\hline 1953 & & 0,2 & 8,7 & 2,0 & 10,2 \\
\hline 1954 & & 7,9 & 8,7 & 11,1 & 8,4 \\
\hline 1955 & & 7,7 & 10,6 & 4,0 & 3,9 \\
\hline 1956 & & $-2,4$ & 6,9 & 1,6 & 5,1 \\
\hline 1957 & & 9,3 & 5,7 & 9,6 & 7,8 \\
\hline 1958 & & 2,0 & 16,3 & 7,0 & 6,1 \\
\hline 1959 & & 5,3 & 11,9 & 9,4 & 9,6 \\
\hline 1960 & & 4,9 & 9,6 & 5,9 & 17,3 \\
\hline 1961 & & 7,5 & 10,6 & 7,0 & 3,3 \\
\hline 1962 & & 5,5 & 7,8 & 5,8 & 8,4 \\
\hline 1963 & & 1,0 & 0,2 & 0,0 & 7,8 \\
\hline 1964 & & 1,3 & 5,1 & 1,1 & 1,6 \\
\hline 1965 & & 13,8 & $-4,7$ & 1,6 & 1,8 \\
\hline 1966 & & $-3,1$ & 11,7 & 7,7 & 6,6 \\
\hline 1967 & & 5,6 & 3,0 & 4,4 & 7,8 \\
\hline 1968 & & 1,4 & 15,5 & 11,7 & 8,8 \\
\hline 1969 & : & 6,0 & 10,7 & 8,8 & 11,6 \\
\hline 1970 & & 5,6 & 11,1 & 8,9 & 14,9 \\
\hline 1971 & & 11,3 & 12,0 & 13,1 & 10,1 \\
\hline 1972 & & 4,1 & 13,0 & 11,4 & 13,5 \\
\hline 1973 & & 3,6 & 16,3 & 12,9 & 21,0 \\
\hline 1974 & & 8,2 & 9,2 & 9,7 & 17,5 \\
\hline 1975 & 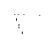 & 4,8 & 5,9 & 2,7 & 13,7 \\
\hline 1976 & & 2,9 & 12,4 & 7,3 & 14,5 \\
\hline 1977 & & 11,8 & 3,9 & 4,7 & 9,4 \\
\hline 1978 & & $-2,6$ & 7,2 & 4,2 & 9,6 \\
\hline 1979 & & 5,0 & 6,4 & 5,4 & 13,9 \\
\hline 1980 & & 6,3 & 7,9 & 6,8 & 10,1 \\
\hline 1981 & & 6,4 & $-5,5$ & $-2,8$ & 0,2 \\
\hline 1982 & & $-2,5$ & 0,6 & 0,9 & 5,6 \\
\hline 1983 & & 2,2 & $-6,8$ & $-3,5$ & 0,1 \\
\hline 1984 & & 8,8 & 8,9 & 8,9 & 10,8 \\
\hline
\end{tabular}

FONTE: (dados básicos): Contas Nacionais - Fundaçăo Getúlio Vargas e Revista Conjuntura Económica (set. 1971, mar.1985, mai.1987) 
TABELA 4 - BALANÇO DE PAGAMENTOS DO BRASIL - PRINCIPAIS CONTAS - Taxas médias de crescimento anual - periodos selecionados ( $\%$ a.a.)

\begin{tabular}{|c|c|c|c|c|}
\hline & $1981 / 83$ & $1981 / 85$ & $1983 / 85$ & $1984 / 85$ \\
\hline 1. Exportações & $-3,04$ & 2,43 & 8,20 & $-5,06$ \\
\hline 2. Importaçōes & $-16,41$ & $-12,15$ & $-7,67$ & $-5,48$ \\
\hline 3. Rendas de capitais & & & & \\
\hline $\begin{array}{l}\text { (llquido) } \\
\text { 4. Juros lfquidos }\end{array}$ & $\begin{array}{l}3,43 \\
2,13\end{array}$ & $\begin{array}{l}2,28 \\
1,33\end{array}$ & $\begin{array}{l}1,13 \\
0,54\end{array}$ & $\begin{array}{l}-1,85 \\
-5,30\end{array}$ \\
\hline 5. Investimentos & 2,10 & & & \\
\hline $\begin{array}{l}\text { Diretos Líquidos } \\
\text { 6. Empréstimos e }\end{array}$ & $-46,39$ & $-25,28$ & 4,13 & $-33,15$ \\
\hline Financiarnentos & $-34,49$ & $-17,97$ & 2,72 & $-31,95$ \\
\hline 7. Amortizações & 3,25 & 7,17 & 11,23 & 31,28 \\
\hline
\end{tabular}

FONTE: Relatórios do Banco Central (diversos números)

1 - Balanço de Serviço de Fatores

Obs. - Para perlodos selecionados entre 1947 e 1981, ver CRUSIUS (1983) 


\section{TABELA 5 - DECOMPOSIÇÃO PERCENTUAL DO INVESTIMEN- TO GLOBAL - 1947/1985}

\begin{tabular}{|c|c|c|}
\hline Anos & $\begin{array}{c}\text { FBCF do Governo/ } \\
\text { FBCF total } \\
\%\end{array}$ & $\begin{array}{c}\text { FBCF das empresas/ } \\
\text { FBCF total } \\
\%\end{array}$ \\
\hline $\begin{array}{l}1947 \\
1948 \\
1949 \\
1950 \\
1951 \\
1952 \\
1953 \\
1954 \\
1955 \\
1956 \\
1957 \\
1958 \\
1959 \\
1960 \\
1961 \\
1962 \\
1963 \\
1964 \\
1965 \\
1966 \\
1967 \\
1968 \\
1969 \\
1970 \\
1971 \\
1972 \\
1973 \\
1974 \\
1975 \\
1976 \\
1977 \\
1978 \\
1979 \\
1980 \\
1981 \\
1982 \\
1983 \\
19841 \\
1985\end{array}$ & $\begin{array}{l}14,5 \\
22,5 \\
26,5 \\
28,4 \\
20,3 \\
19,1 \\
21,1 \\
19,8 \\
20,9 \\
19,0 \\
27,5 \\
28,9 \\
23,2 \\
27,1 \\
24,8 \\
25,2 \\
23,2 \\
25,3 \\
29,9 \\
26,1 \\
30,9 \\
24,6 \\
33,9 \\
18,4 \\
17,2 \\
15,5 \\
15,2 \\
14,5 \\
13,8 \\
15,1 \\
13,1 \\
12,4 \\
10,5 \\
10,0 \\
17,7 \\
11,0 \\
14,0 \\
11,4 \\
12,6\end{array}$ & $\begin{array}{l}85,5 \\
77,5 \\
73,5 \\
71,6 \\
79,7 \\
80,9 \\
78,9 \\
80,2 \\
70,1 \\
81,0 \\
72,5 \\
71,1 \\
76,8 \\
72,9 \\
75,2 \\
74,8 \\
76,8 \\
74,7 \\
70,1 \\
73,9 \\
69,1 \\
75,4 \\
66,1 \\
81,6 \\
82,8 \\
84,5 \\
84,8 \\
85,5 \\
86,2 \\
84,9 \\
86,9 \\
87,6 \\
89,5 \\
90,0 \\
82,3 \\
89,0 \\
86,0 \\
87,4 \\
86,2 \\
\end{array}$ \\
\hline
\end{tabular}

FONTE (dados brutos): Contas Nacionais, Fundação Getúlio Vargas, Revista Conjuntura Económica (set. 1971, jun. 1974, maio/1987)

1 - Para os anos de 1984 e 1985, náo foi considerada a rubrica "Outros", considerada separadamente nas Contas Nacionais da FCV. 


\section{TABELA 6 - FORMAÇÃO BRUTA DE CAPITAL FIXO - FBCF/PIB $-1967 / 85$}

\begin{tabular}{rrrrrr}
\hline Anos & $\begin{array}{c}\text { Preços correntes } \\
\text { Cr\$ milhões }\end{array}$ & $\begin{array}{c}\text { FBCF/PIB } \\
\text { ern \% }\end{array}$ & $\begin{array}{r}\text { Preços 1980 } \\
\text { Cr\$ milhões }\end{array}$ & $\begin{array}{r}\text { Variação } \\
\text { anual \% }\end{array}$ & $\begin{array}{r}\text { FBCF/ } \\
\text { PIB \% }\end{array}$ \\
\hline 1967 & $16.667,0$ & 19,3 & 775.000 & 4,6 & 18,7 \\
1968 & $25.992,0$ & 21,2 & 917.000 & 18,3 & 19,9 \\
1969 & $35.805,0$ & 22,1 & 1.040 .000 & 13,4 & 20,6 \\
1970 & $36.598,0$ & 18,8 & 1.115 .000 & 7,2 & 20,3 \\
1971 & $51.420,0$ & 19,7 & 1.286 .000 & 15,3 & 21,0 \\
1972 & $70.468,0$ & 20,2 & 1.501 .000 & 16,7 & 21,9 \\
1973 & $104.253,0$ & 21,4 & 1.816 .000 & 21,0 & 23,2 \\
1974 & $162.778,0$ & 22,8 & 2.056 .000 & 13,2 & 24,1 \\
1975 & $244.840,0$ & 24,3 & 2.256 .000 & 9,70 & 25,1 \\
1976 & 365.516 .0 & 22,5 & 2.410 .000 & 6,8 & 24,5 \\
1977 & $529.626,0$ & 21,3 & 2.375 .000 & $-1,4$ & 23,0 \\
1978 & $788.878,0$ & 21,8 & 2.449 .000 & 3,1 & 22,7 \\
1979 & $1.375 .102,0$ & 22,8 & 2.565 .000 & 4,7 & 22,1 \\
1980 & $2.781 .575,0$ & 22,0 & 2.782 .000 & 8,5 & 22,0 \\
1981 & $5.485 .281,0$ & 22,2 & 2.413 .000 & $-13,3$ & 19,7 \\
1982 & $9.907 .402,0$ & 20,6 & 2.282 .000 & $-5,4$ & 18,5 \\
1983 & $20.208 .435,0$ & 17,1 & 1.894 .000 & $-17,0$ & 15,8 \\
1984 & $64.162 .487,0$ & 16,5 & 1.971 .000 & 4,1 & 15,5 \\
1985 & $253.711 .722,0$ & 18,0 & 2.200 .000 & 11,6 & 16,0 \\
\hline
\end{tabular}

FONTE: Contas Nacionais - Fundação Getúlio Vargas, Revista Conjuntura Econômica (dez. 1979, maio/1987)

Obs. - séries equalizadas por relativos. 


\section{GRÁFICO I}

\section{AS FASES DOS CICLOS DA ECONOMIA BRASILEIRA}

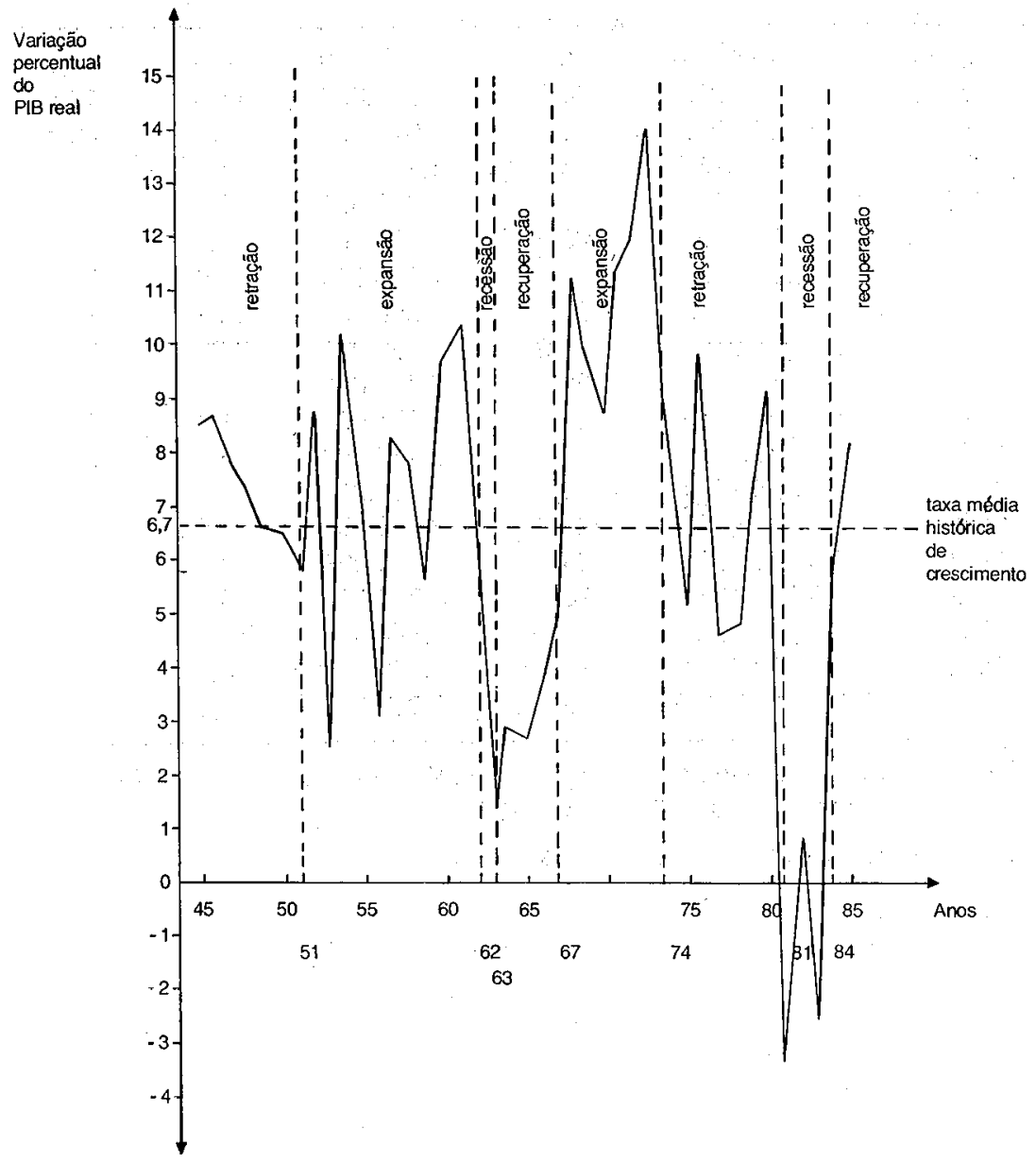

FONTE: Tabela 1, elaborada pela autora. 


\section{GRÁFICO II}

\section{ÍNDICE DE RELAÇÃO DE TROCAS}

$$
(1977=100)
$$

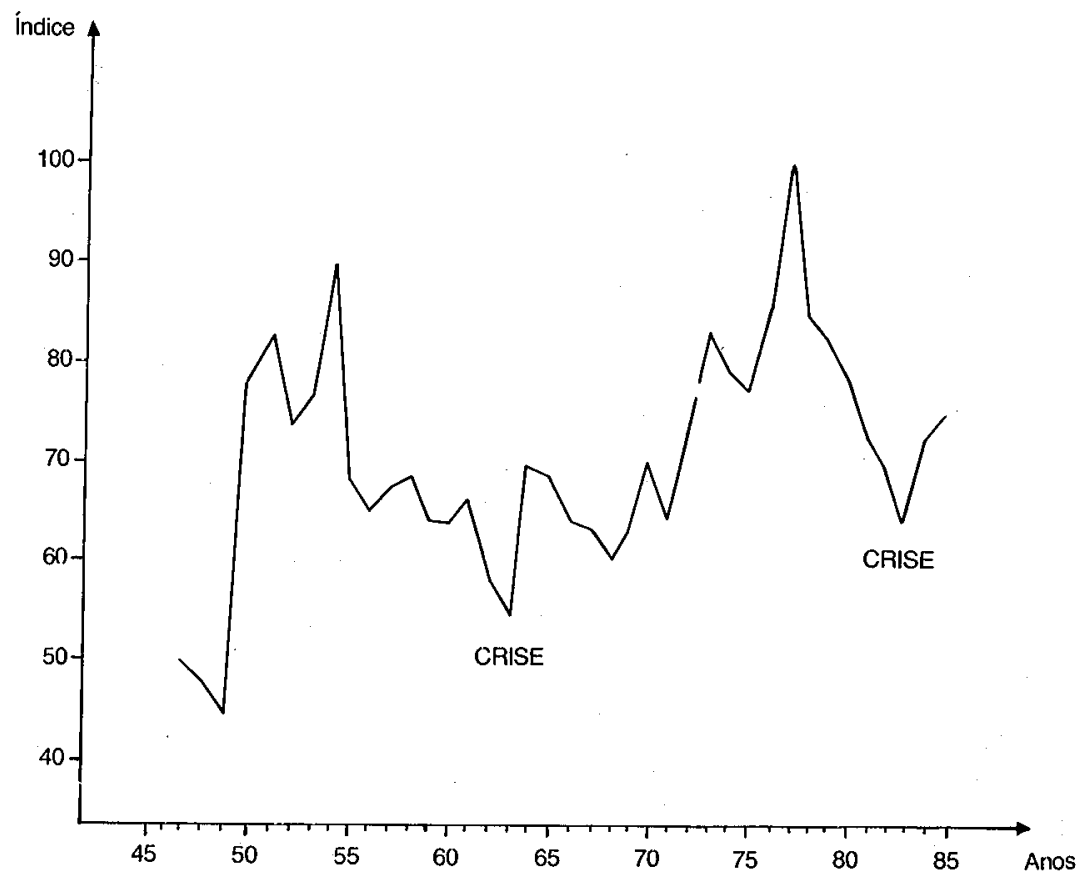

FONTE (dados brutos): Boletim do Banco Central, diversos números (1947/53 In: SERRA, 1982) 


\section{GRÁFICO III}

\section{PREÇOS - ICP. DI - COLUNA 2 - 1945/85}

Taxas anuais de veriação

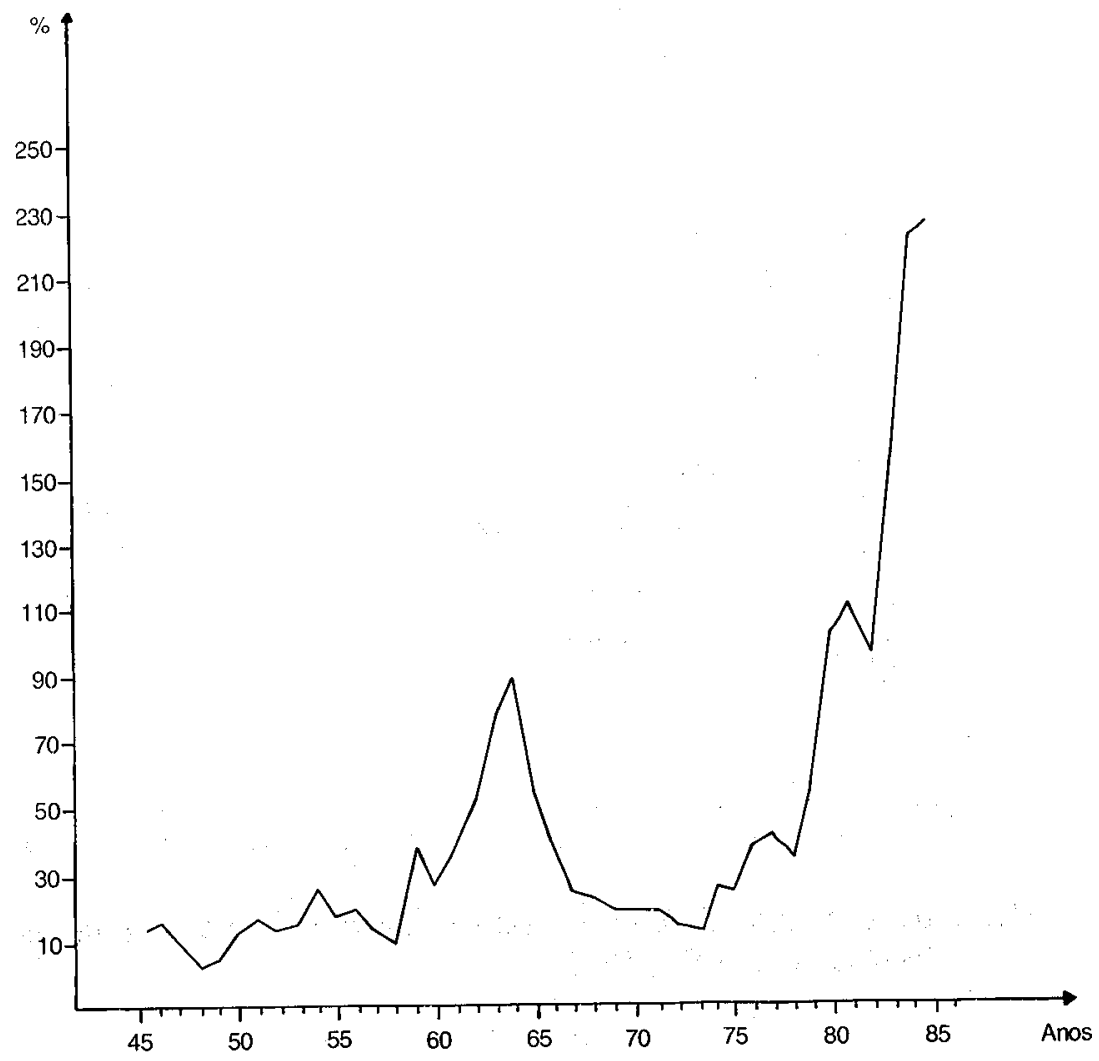

FONTE: Fundação Getúlio Vargas, Revista Conjuntura Econômica, diversos números 


\section{BIBLIOGRAFIA}

BACHA, Edmar. Choques Externos e Perspectivas de Crescimento: o Caso do Brasil - 1973-78. Pesquisa e Planejamento Econômico, Rio de Janeiro, 14(3):583-622, dez.1984.

BOBER, Stanley. Los Ciclos y el Crecimiento Económico. Buenos Aires, Amorrortu, 1971. 296p.

CEPAL/UNIDO de Desarrollo Industrial, Division Conjunta. Reflexiones Sobre Industrialización, Articulación y Crecimiento. Revista de la Cepal, Santiago de Chile, n.28, p.49-52, abr.1986.

CONTADOR, Cláudio R. \& HADDAD, Cláudio L. Produto Real, Moeda e Preços: a Experiência Brasileira no Perlodo 1861-1970. Revista Brasileira de Estatística, Rio de Janeiro, 36(143):407-40, jul/set.1975.

COUTINHO, Luciano G. Inflexões e Crise da Polftica Econômica: 1974-1980. Revista de Economia Política. 1(1):77-100, jan/mar.1981.

COUTINHO, Luciano G. \& REICHSTUL, Henri-Philippe. O Setor Produtivo Estatal e o Ciclo. In: MARTINS, Carlos Estevan (org.) Estado e Capitalismo no Brasil, São Paulo, Hucitec/Cebrap, 1977, p.55-95.

- Investimento Estatal 1974-1980: Ciclo e Crise. In: BELUZO, Luiz Gonzaga M. \& COUTINHO, Renata (orgs.) Desenvolvimento Capitalista no Brasil. Sāo Paulo, Brasiliense, 1983, v.2, p.38-58.

CRUSIUS, Yeda Rorato. Dívida Externa Brasileira: Elementos Para Discussão. Análise Econômica. Porto Alegre, UFRGS, 1:23-53, mar. 1983.

ESTEY, James. Ciclos Econômicos: sua Natureza, Causa e Controle. 3.ed. São Paulo, Mestre Jou, 1965. 542p.

FONSECA, Pedro Cezar Dutra. A Política Econômica Governamenta! e os Ciclos: Reflexões Sobre a Crise Atual. Estudos Econômicos. 14(2):247-58, maio/ago.1984.

RODRIGUES, D.G. O Comportamento Macroeconômico e o Desempenho Setorial da Indústria: 1970/83. Revista Brasileira de Mercado de Capitais, 10(29):65-88, jan/mar.1984. 
SERRA, José. Ciclos e Mudanças Estruturais na Economia Brasileira no Pós-Guerra. Revista de Economia Política, 2(6):5-45, abr/jun.1982.

Ciclos e Mudanças Estruturais na Economia Brasileira no Pós-Guerra: a Crise Recente. Revista de Economia Política, 2(3):111-35, jul/set.1982.

SUZIGAN, Wilson et. alii. Crescimento Industrial no Brasil - Incentivos e Desempenho Recente. Rio de Janeiro, IPEA/INPES, 1984. 281p.

TAVARES, Maria da Conceição. Ciclos e Crise: Movimento Recente da Industrialização Brasileira. Rio de Janeiro, UFRJ, 1978. (Tese Concurso Titular).

O Sistema Financeiro Brasileiro e o Ciclo de Expansão Recente. In: BELUZZO, Luiz Gonzaga M. \& COUTINHO, Renata (orgs.) Desenvolvimento Capitalista no Brasil. São Paulo, Brasiliense, 1983. v.2, p.107-38.

TAVARES, Maria da Conceição \& BELLUZZO, Luiz Gonzaga de Mello. Notas Sobre o Processo de Industrialização Recente no Brasil. In: BELLUZZO, Luiz gonzaga M. \& COUTINHO, Renata (orgs.) Desenvolvimento Capitalista no Brasil. São Paulo, Brasiliense, 1982, v.1, p.122-40. 